A very interesting discussion followed the reading of the report, but a great part of this it would be useless to give, as many details of the trial have necessarily been omitted from our brief abstract.

A paper was next read "On Condensation in Steam-Engine Cylinders during admission." This was a contribution by Lieutenant-Colonel English, of Jarrow. In former papers on this subject the author had given experimental data, but it was objected that he had left out of account the range of temperature in the cylinder. In order to show that this was not the case, he submitted the following formulr, which, he claimed, proved his case. The former papers, a study of which is necessary to a proper understanding of the facts, may be found in the Transactions of the Institution for the years 1887 and 1889

In jacketed cylinders the weight of steam condensed per stroke and not re-evaporated at cut-off is represented by the expression

$$
\frac{56}{\sqrt{\text { revs. per second }}} \times \frac{\left(\mathrm{S}_{c}-\mathrm{S}_{1}\right)}{\mathrm{L}} \rho_{1} \text {, }
$$

where $S_{c}$ is the unjacketed clearance surface in square feet, $S_{1}$ the fresh surface exposed during admission up to cut-off, $\rho_{1}$ the initial density of the steam in pounds per cubic foot, and $L$ the latent heat of evaporation in thermal units. If $d$ be the diameter of the cylinder in feet, $l$ the length of stroke in feet, $m$ the proportion of struke up to cut-off, $\mu=\frac{\mathrm{S}}{2 \times \text { area of cylinder }}$, and $\mathrm{N}$ the number of revolutions per minute; then $\mathrm{S}_{c}=$ unjacketed clearance surface $=\frac{\mu \pi d^{2}}{2} ; \mathrm{S}_{1}=\pi d m l ;$ 人'revs. per second $=\frac{\sqrt{N}}{7.75}$; and the foregoing expression may be written

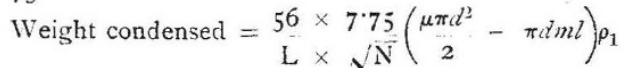

$$
\begin{aligned}
& =\ldots 868 \sqrt{\mathrm{N}}\left(\frac{\mu}{m l}-\frac{2}{d}\right) \frac{\pi d^{2} m l}{4}-\rho_{1} \text {. }
\end{aligned}
$$

But $\pi i^{2} m l-\rho_{1}$ is the weight of steam per stroke uncondensed at cut-off, and 868 may be taken as an approximate value for L; therefore for jacketed cylinders;

$$
y=\frac{\text { weight condensed }}{\text { weight uncondensed }}=\frac{t}{\sqrt{N}}\left(\frac{\mu}{m l}-\frac{2}{d}\right) .
$$

For unjacketed cylinders a similar approximate expression is

$$
y=\frac{1 \cdot 5}{\sqrt{N}}\left(\frac{\mu}{m l}-\frac{2}{d}\right) \text {. }
$$

The author supported his views by means of a voluminous table, in which he gathered together the observed data on a number of steam-engine trials made by various well-known authorities, to which he attached the results obtained by calculation on his system.

A short discussion followed the reading of this paper, and the meeting was then brought to a conclusion by the usual yotes of thanks.

The summer meeting of the Institution will be held at Portsmouth, on July 26 to 29 .

\section{THE ROYAL SOCIETY SOIREE.}

THE annual soirce of the Royal Society, which took place on Wednesday, May 4, may be said to have been the most successful that has been held for many years. All the necessary arrangements, which were by no means few in number, were carried out without a hitch, while the exhibits were of a most attractive nature. As regards the latter, the following are few notes of the most novel and important objects displayed :-

Prof. T. E. Thorpe exhibited a model to illustrate the general phenomena of explosions as brought about by the presence of dust particles, in explanation of the causes of colliery explosions. This apparatus consisted of two long narrow boxes, fitted together in the form of a cross. On the bottom of these boxes was thinly strewn a quantity of fine Lycopodium powder, while at one end of the longer box there was a small chamber in which a blank cartridge was fired. The firing of this cartridge corresponded to the direct action of a "blow-out shot," while the dust raised

No. 1 I 76 , vol. 46$]$ by the concussion, which carried the flame throughout the entire apparatus, took the place of the fine coal dust. The apparatus also showed that the progress of such an explosion was always accompanied with increase of violence.

Prof. Clowes showed an ordinary miner's safety-lamp which had, by a very simple contrivance, been converted into a delicate instrument for detecting minute proportions of fire-damp. To the ordinary burner an additional tube is made to pass through the oil reservoir, one end of it being connected, by means of a flexible tube, with a small portable bottle of compressed hydrogen. The hydrogen when turned on becomes ignited close to the oil burner, the flame of which is extinguished by turning down the wick; by adjusting the flame of hydrogen to the standard height, a luminous column of light is seen vertically over it, from the behaviour of which the amount of inflammable gas can be directly estimated. At the conclusion of the experiment the wick is simply turned up, and ignited from the hydrogen flame; the latter is then disconnected from the bottle. From 0.25 to 3 per cent. of fire-damp has in this way been estimated, while greater quantities than these have been measured by reducing the size of the flame.

Vacuum tubes without electrodes, exhibited by Dr. Bottom. ley, These tubes, which were of a variety of shapes and kinds, illustrated very beautifully all the phenomena of stratification. They were sensitive also to magnetic and electro-dynamic influence, and showed the phenomena of molecular bombardment. The brilliant illumination of a piece of Iceland spar contained in a glass sphere afforded an excellent means of displaying the elecrical excitements. [For an account of experiments with vacuum tubes, see a letter by Mr. Bottonley in NATURE, January 6, I88I, vol. xxiii. p. 218.]

$\mathrm{Mr}$. Cecil Carus-Wilson exhibited some natural and artificial sands, from which he was able to produce many musical notes. These notes, as he explained, were the results of the rubbing together of the surfaces of the grains of sand, but he had met with several sands from which he could not obtain a vestige of a note. One special artificial sand sang only when rubbed in some sort of vessel.

Apparatus for measuring degrees of incompleteness of colour vision, exhibited by Mr. Brudenell Carter. The object used for the tests is a group of various colours, which were such that they could be seen by either reflected or transmitted light. The amount of illumination that was required to recognize the colours distinctly was a measure of the "degree of incompleteness." In order to control this amount of illumination, light of known intensity had to pass through a variable aperture before it fell on the test object, the size of this aperture being read off in square millimetres.

Captain Weir's azimuth diagram was exhibited by Mr. J. D. Potter. It is claimed for this diagram that besides being most ingenious, it furnishes one of the most successful modes of graphic solution of a mathematical problem that has ever been invented. It is used for finding the true azimuth of a heavenly body, taking into account the ever-changing errors of the compass, which in our days of iron ships have to be so carefully watched and recorded. The errors as usually determined are obtained from observations made of the compass-bearing of a heavenly body (the sun generally being taken) with its true bearing, and it is for the simplification of this method that this azimuth diagram has been found to be practically useful.

Prof. Oliver Lodge had three exhibits. The first was the projection of interference bands on a screen, being produced by a modified method of Michelson. Very striking also were the electric sparks in and to water, illustrating lightning effects and multiple flashes. In a shower, with too great spark-length for a strong discharge, a multitude of violet streams or spurts filled the air, resembling somewhat lightning flashes. The spark to water spread itself out over the surface, shouing that the surface layer was a feeble dielectric, while the spark under water u as hrief lut very viulent, treating the water as a dielectric, and producing concussion. The electric retina, illustrating the possible meaning of the rod-and-cone structure, was very interesting; radiation from spheres which were in a suddenly disturbed and oscillatory electrical condition falling upon a graduated series of end-on cylinders, which responded by vibrating transversely.

Mr. W. Crookes repeated many of those beautiful experiments of electric currents of high potential and extreme frequency that were first carried out by Tesla. The discharges from a battery of Leyden jars were sent through the primary 
wire of an oil induction coil. The frequence of alternation amounted to no less than $1,000,000$ a second, while the electromotive force reached the enormous amount of 100,000 volts. Perhaps it was as well that this frequency was great, otherwise the physiological action might have been rather surprising to those who trusted implicitly in Mr. Crookes. The resistance offered by the sheet of vulcanite to the strong current produced some fine flashes, while very pretty were the examples of brush discharges, St. Elmo's fires, \&c., at the secondary poles of the oil induction coil.

The electrical apparatus shown by Captain Holden, R.A., consisted of some very important new instruments, among which we may mention the high-speed chronographic pen for taking a number of successive records of short intervals of time, the pen being automatically reset after each record; an improved simple compensated voltmeter on the hot wire system, and the dead-beat alternating current ammeter worked by a heated metal strip and free from self-induction.

Prof. Roberts-Austen exhibited a new electrical method for the exact determination of very high temperatures, which has rendered possible the construction of a very simple instrument, devised by Prof. H. Le Chatelier, that can be placed in the hands of any workman. The latter depends on the comparison of the intensity of the radiation emitted by a glowing body (the temperature of which has to be determined) with that of a standard source of light. To use the instrument it is pointed in such a direction as to have the light from the heated mass of metal in its field of view, so that the colour can be distinctly observed in the same field of view a series of standard colours can also be made apparent (situated side by side with the heated metal), by turning a milled head screw which carries a pointer over a graduated scale. By matching the colours a direct reading of the position of the pointer gives the required temperature.

The Rev. F. J. Smith exhibited an electric tram chronograph which he had devised for measuring small periods of time, varying from one-fourth to one-twenty-thousanth part of a second. This instrument consists of a metal girder furnished with a T-shaped end, carries two steel rails, and is supported on a $\mathbf{V}$-groove, hole, and plane system. The carriage, on which is fixed a slightly smoked glass plate, runs on these rails, driven either hy a weight or by a coiled spring. A metal pillar, carried on a V-groove, hole, and plane system, is placed in front of the moving surface, and supports electro-magnetic styli which can be brought into contact with the smoked surface; a tuning-fork also is so placed that the traces are found to be recorded on the smoked plate so as to afford a means of measuring the time intervals. The two motions of the pillar, of rotation and vertical translation, allow a large number of observations to be made on the same plate. There are also continuous contact-breakers, whereby, when a photographic plate is fixed in the carriage, spark photographs of moving objects may be obtained. This instrument has been applied to the measurement of the velocity of projectiles, and small periods of time in physiological research, and to the photography of insects and falling drops of liquids.

Perhaps the most unique exhibit of the evening was the series of photographs of flying.bullets which Mr. Boys had obtained by a modification of an old method. The photographs showed beautifully the waves in the air caused by the rapid flight of the bullet analogous to those produced by a fast-going steamer. In one slide the small pieces of paper through which the bullet had passed were also seen ploughing their way through the air, producing quite as definite waves as the projectile itself, only of not such large dimensions. The passage of a bullei through a piece of wire was also very curious, the piece of wire that was cut off not having time to fall before it was seized by the lightning eye of the camera. The photograph showing a magazine rifle bullet piercing a glass plate brought out some very interesting facts. The glass appeared to be thoroughly scattered in a direction opposite to that in which the bullet was proceeding, the greatest scattering taking place on the side which the projectile touched first. The waves set up on the glass plate gave measures of the wave, length of the tremor caused, and the velocity of travel. The bullets used for these pictures were of various kinds, and the velocities varied from 750 to as much as 3000 feet per second, the former from a pistol and the latter from a magazine rifle, the bullet being composed of aluminium to obtain this great velocity.

The C mmittee of the Kew Observatory exhibited a testing camera for photographic objectives that had been designed by
Major L. Larwin. With this instrument all the most important features of a lens can be accurately and swiftly determined. We may mention here that arrangements are being made that any lens sent to them will be thoroughly examined in all respects under the superintendence of Mr. G. M. Whipple, certificates of examination being made out, as is at present done in the case of other instruments.

We must now pass on to the photographs.

Astronomy was well to the fore with the exhibits of Messrs. Lockyer and Roberts. The former showed a fine spectrum of Nova Aurigæ, that had been enlarged twenty-five times from a negative taken with only a 6 -inch object-glass and prism by the Brothers Henry and Hilger respectively; several fine photographs of stellar spectra illustrating the main evolutionary types according to the metteoritic hypothesis, and photographs of the 3 -foot reflector at Kensington that is now near completion. Mr. Roberts showed some photographs of celestial objects; the original negative of Nova Cygni, taken with a 20 -inch reflector with a two-hours' exposure, showing the Nova as a star of the thirteenth magnitude. An enlargement of the region in which Nova Auriga was situated when the star was of the fourth magnitude was also displayed, together with the original photograph taken with the instrument before mentioned, but with an exposure of three hours.

The photographs showing the great sun-spot of February last, exhibited by the Solar Physics Committee, may be said to be the best series that has ever been obtained. The series included nine days, and showed the remarkable changes that occurred during the interval from February 5 to February 17 .

Mr. W. Saville-Kent exhibited a series of photographs, over a hundred, taken by himself, enlargements of the same, and watercolour sketches, illustrating coral reefs, coral animals, and the marine fauna generally of the Great Barrier district of Australia. A lantern exhibition illustrating the same subject was also included in the evening's programme. The reef views, which portrayed extensive areas of growing corals of innumerable varieties, were, as explained by the exhibitor, taken at abnormally low spring tides, and are as a matter of fact very rarely visible to the extent depicted. Among the more important points associated with this exhibit were the facts that in a large number of instances accurate measurements had be en taken of the individual corals that compos ed the reefs photographed, such reefs being in easily accessible positions, where their subsequent amount and rate of growth could be periodically determined. This exhibit, more particularly with relation to the illustrations of living coral polyps-those of the mushroom corals, genus Fungia, being particularly noteworthy-represented the first occasion in which photography has been systematically applied to this highly interesting biological subject. A second novelty exhibited by Mr. Saville-Kent was a pearl of fine quality and considerable size that the exhibitor had caused the motherof-pearl shell animal, Meleagrina margaritifera, to produce by means of a delicately-manipulated operation on the living animal.

From the Zimbabwe ruins, Mashonaland, some very valuable finds in the shape of pottery, gold crucibles, weapons, ingot moulds, \&c., were exhibited by Mr. Theodore Bent and the Royal Geographical Society ; while by the same exhibitors were shown a model of the circular temple at Zimbabwe, built of small blocks of granite without mortar; and several plans of ruins in Mashonaland. No less interesting also were the photographs of ancient Central American monuments and buildings from the ruins at Chichén Itzá (Yucatan), Palenque (Chiapas), \&c., exhibited" by Mr. Alfred P. Maudslay; and a selection from the proof-plates to the first memoir of the archæological survey of Egypt that is being undertaken by Mr. Percy E. Newberry, One of these proot-plates showed all the successive stages of a wrestling match between a black and a white man, more than a hundred different positions being recorded; the white man, we are sorry to say, seemed to be getting the worst of it in many of them.

Several important discoveries were made during the Royal Dublin Society's survey of the fishing grounds on the west coast of Ireland ; specimens of several fish then obtained were exhibited by Prof. A. C. Haddon and Mr. E. W, L. Holt. Many new to British waters were found, while one quite new to science (Nettophichthys retropinnatus, Holt) was caught.

Some very curious worms composed Mr. F. E. Beddard's exhibit. They were specimens of Branchiura Sowerbii, and were found in a tank in the Regent's Park Botanical Gardens.

No. I I 76, vOL. 46] 
They possess a dorsal and ventral series of contractile gills, which make them differ from all other known fresh-water worms.

To summarize shortly a few of the other exhibits, we may mention Messrs. Pike and Harris's high tension apparatus; Mr. H. L. Callendar's platinum resistance pyrometers; the original specimen of Asteropecten Orion (Forbes), and a specimen of a slab of mountain limestone Bolland showing the passage of a foraminiferal ooze into crystalline calcite, by Prof. W. C. Williamson; Prof. Percy Frankland's crystals of active calcium glycerate (lævorotatory); and the two exhibits of turacin, one by Dr. C. A. MacMunn, showing the very remarkable spectrum it produces; the other by Prof. A. H. Church, who discovered this red pigment in the wing-feathers of certain plantain-eaters or Touracos. A very ingenious process of so-called colour photography was explained by Mr. F. Ives, of Philadelphia, who showed several pictures by means of a special optical lantern.

\section{THE SOUTH LONDON ENTOMOLOGICAL AND NATURAL HISTORY SOCIETY.}

THE annual Exhibition of this Society was held on the 5 th 1 and 6th inst., at "The Bridge House," London Bridge, S.E. The President, Mr. C. G. Barrett, F.E.S., in opening the Exhibition, gave a short account of the history of the Society from its formation by eleven South London entomologists in 1872 ; and he referred to the work done by members in rendering popular the study of biological science.

The exhibits were arranged in four rooms, and were very varied, including examples of nearly every order of the animal and vegetable kingdoms.

In the first room Mr. C. S. Cooper exhibited an almost perfect collection of British wild flowers and leaves; the Lambeth Field Club, Mollusca; Mr. J. T. Carrington, land shells from the Riviera, arranged so as to show variation; Mr. C. H. Collings a d Mr. D. W. Collings, British and Australian birds' eggs aud British birds; Mr. H. J. Turner and Mr. Rice, nests and egys of British birds, the latter having a double nest of the great titmouse (Parus major). The tables around this room were set apart for the exhibition of objects by aid of the microscope, and among so many it is difficult to make a selection; but the more important objects were those of Mr. T. D. Ersser, who showed the circulation of the blood in a gold carp, a most interesting subject; Mr. J. H. Stanley, spawn of perch; Mr. H. Groves, the circulation of sap in Nitella ; Mr. R. Macer, heads and eyes of various species of spider; Mr. West, freshwater Polyzoa; Mr. E. Hinton, preparations of the Hydroids, including the beautiful sea pen, killed with the tentacles fully extended; $\mathrm{Mr}$. W. B. Medland, the pulsation in the heart of a snail ; Mr. J. B. Medland, a section of the jaw of a mole, with the teeth in situ (polarized).

In the second room Mr. J. A. Cooper's birds' nests and eggs in natural clutches occupied one end, and were much admired: one of the principal features of this collection being that it is arranged to show the variation in different clutches of the eggs in one species. This was particularly noticeable in those of the red-backed shrike. Among the eggs there were white varieties of those of the chaffinch, lapwing, and great blackbacked gull ; variable series of the guillemot, razorbill, lapwing, and golden plover; also a series of nests containing eggs of the cuckoo, including nests of the wagtail, tree pipit, chaffinch, greenfinch, hedge sparrow, robin, flycatcher, yellow bunting.

In the class Insecta some of the more important exhibits were those of Mr. J. H. Leech, with sixteen drawers containing Palæarctic Lepidoptera. This collection attracted considerable attention. Mr. J. Jenner Weir showed exotic Rhopalocera, illustrating forms of mimicry, and fine examples of South African Ornithoptera. Mr. S. Edwards also contributed a large exhibit of exotic Rhopalocera. Adjoining these, was the Society's typical collection of Canadian Lepidoptera. Four drawers of European Neuroptera were shown by Mr. R. McLachlan. Mr. H. Moore exhibited a number of wasps' nests. Mr. T. R. Billup's exhibit comprised British Coleoptera, con= taining types of nearly all the known species; three drawers of Hemiptera-Heteroptera and one of Homoptera were beautifully arranged, and the adoption of a system of labelling giving the name of the species, the locality where taken, and date of capture, is much to be commended; seven drawers of Hymenoptera Aculeata, containing many rare species, also long series of Ichneumonidæ, many of the specimens being new to science, and others new to
Britain ; also two drawers of life-histories of Hymenopterous and Dipterous parasites, together with the larvæ and imagines of the Lepidopterous host. This last exhibit was one of the most interesting and instructive of the exhibition. Of British Lepidoptera there was a magnificent display, there being some forty exhibitors. Mr. R. South showed nearly the whole of his collection of Pyrales, Crambi, Pterophori, and Tortrices, a selection of Noctua, among which were extreme series of most of the polymorphic species in the group ; a drawer of Ly'cena icarus, showing the colour range of both sexes, one very blue female without black discoidal spots was especially interesting; a drawer of Geometræe showing that the colour and ornamentation of the female parent is transmitted to a large proportion of her offspring; Mr. C. G. Barrett, Pieris napi, one female of a light canary-yellow colour from Norfolk, others suffused with grey from South Wales, others with black spots and tips and dark nervures from the north of Ireland ; varieties of Anthocharis cardamines; long series of Odonestis potatoria, showing extreme variation, the colour in the males ranging from chocolate 10 a pale buff; also extensive series of varieties of Agrotis cursoria and A. tritici, from the east coast of England. Mr. Barrett also exhibited a drawer of varieties of Rhopalocera lent to him for the purpose of figuring in his book on the British Lepidoptera, by the Rev. Joseph Greene, the Rev. O. Pickard Cambridge, Dr. Wheeler, Mr. J. E. Robson, Mr. E. Sabine, and Mr. Sydney Webb. It is doubtful whether such a collection of varieties has been seen before, and those Lepido. pterists who pay special attention to the question of variation were much interested in the extraordinary varieties shown. $\mathrm{Mr}$. F. Merrifield, examples of Selenia illustraria, S. illunaria, S. lunaria, Eugonia alniaria, Vanessa urtice, Platypteryx falcataria, Arctia caia, Bombyx quercus and var. callune, bred by him in his experiments on the effect of temperature on the pupæ of certain species in causing variation. Labels were attached to each specimen showing the conditions to which the pupe had been subjected, and the results obtained from these. It appeared that a lower temperature produced examples which were darker and more intense in colour than those subjected to higher temperatures. A third drawer of $S$. illustraria and $S$. illunaria was shown, as illustrations of the effect of temperature applied for a very few days to pupæ at a sensitive stage, i.e. just before they began to show the colour, the forcing temperature was about $77^{\circ}$; the natural temperature about $40^{\circ}$ to $50^{\circ}$; a range of $15^{\circ}$ or less (at a point which it appeared was not yet actually ascertained between $57^{\circ}$ and $73^{\circ}$ ) was sufficient to produce the full temperature effects shown in the first two cases, but a range of much less than $13^{\circ}$, if at the right part of the thermometric scale, produced substantial difference of colsuring. Mr. W. Farren contributed examples from Cambridge including fine yellow specimens of Bryophila perla, and extensive series of $B$. muralis and $B$. impar of Warren ; these gave rise to considerable discussion among visitors as to whether impar was a true species or only a variety of muralis. Mr. R. S. Standen, a small box showing extreme varieties of Argynnida. Mr. Tugwell, a selection from his cabinet, including long series of Eugonia alniaria, Esp., melanic forms of Phigalia pedaria, Boarmia repandata, Tephrosia biunduilaria, \&c., and striking varieties of Abraxas grossulariata. Mr. C. G. Gregson also put in a magnificent series of varieties of this last-named species, some of the specimens being entirely suffused with the black markings, in others the yellow-coloured markings were wanting, and many were very pale forms, the black markings being absent; Mr. Gregson also showed Dianthacia conspersa, from various localities, to illustrate the local variation in that species-many of the forms were so extreme that he had given them varietal names. Mr. J. R. Wellman, his collection of Dianthœcia and Acidalia, also a drawer of Cidaria russata, bred and captured from various parts of Great Britain, a most interesting drawer as showing local variation. $\mathrm{Mr}$. F. W. Hawes, Rhopalocera, reared in 1890 and 1891 , chiefly from ova obtained by searching or from the captured female, thus enabling Mr. Hawes to ascertain the early life-histories of this group; among them were examples of Hesperia lineola, the species recently added to the British list by Mr. Hawes. Variation in Arctia caia was shown by Mr. Goldthwait, Mr. T. W. Hall, and Mr. A. Mera. Mr. C. H. Williams included in his series a gynandrous specimen of Argynnis paphia taken by him last summer in the New Forest, and much attention was paid to this beautiful specimen. Life-histories, the larvæ being mounted on

No. I I 76 , vOL. 46 ] 